\title{
Vpliv koristnih talnih mikroorganizmov in endofitov na rastlinsko obrambo pred žuželkami
}

\author{
Anamarija JAGODIČ ${ }^{1}$, Matevž LIKAR ${ }^{2}$
}

Delo je prispelo 11. decembra 2018, sprejeto 03. januarja 2019.

Received December 11, 2018; accepted January 03, 2019.

\section{IZVLEČEK}

Številni talni mikroorganizmi, kot so na primer mikorizne glive in rizobakterije, lahko pomagajo rastlinam premagovati biotični in abiotični stres, in sicer s spodbujanjem rasti rastlin in inducirano obrambo. Koristni talni mikroorganizmi delujejo dvosmerno $\mathrm{z}$ nadzemnimi organizmi, kot so herbivori, njihovimi naravnimi sovražniki ter opraševalci. Vloga interakcij med prej omenjenimi organizmi pridobiva $\mathrm{v}$ kmetijstvu in naravnih ekosistemih vse več pozornosti. S tem pa tudi narašča zanimanje za razumevanje molekularnih in fizioloških mehanizmov, ki so $\mathrm{v}$ ozadju tovrstnih multitrofičnih sistemov.

Ključne besede: talni mikroorganizmi; endofiti; interakcije; herbivori; inducirana sistemska obramba; multitrofični sistemi

\author{
ABSTRACT \\ IMPACT OF BENEFICIAL SOIL MICROORGANISMS \\ AND ENDOPHYTES ON PLANT DEFENSE AGAINST \\ INSECTS
}

Soil borne microorganisms such as mycorrhizal fungi and plant growth-promoting rhizobacteria help plants to overcome abiotic and biotic stress. Mechanisms used in this situtations are: growth promotion and induced resistance. Beneficial soil microorganisms also interact with foliar insects (herbivores, natural enemies and pollinators). This kind of interactions are getting more and more important in different ecosystems, especially in agriculture. A better knowledege of these systems would certainly help to deepen the understanding of multitrophic interactions.

Key words: soil borne microorganisms; endophytes; herbivores; induced systemic resistance; multitrophic system

\section{UVOD}

Kmetijstvo se dandanes sooča s številnimi novimi pristopi pri zatiranju gospodarsko pomembnih škodljivih organizmov. Vse več pozornosti se namenja ekološkim pristopom pri varstvu rastlin, prav tako pa je pomembno doseganje večjih pridelkov $\mathrm{z}$ omejevanjem negativnih vplivov na okolje.

Rastline so razvile več načinov obrambe pred škodljivimi organizmi. Pri tem ločimo direktne mehanizme, med katere uvrščamo rastlinske značilnosti, kot so rast trnov ali izločanje toksinov, ki neposredno negativno delujejo na škodljive organizme. Razvile so tudi indirektne mehanizme obrambe, ki vključujejo izločanje hlapnih organskih komponent, ki v neposredno bližino privabljajo naravne sovražnike škodljivih organizmov. Zato lahko trdimo, da imajo rastline vlogo posrednika $\mathrm{v}$ multitrofičnih interakcijah med številnimi vrstami škodljivih in koristnih organizmov (Schoonhoven et al., 2005). Za rastline je značilno tudi to, da povezujejo talne in nadzemne združbe organizmov.

Raznolike združbe talnih mikroorganizmov (endofitske glive, mikorizne glive, rast spodbujajoče glive ter rizobakterije) pozitivno delujejo na rast rastlin in preživetje prek posrednih in neposrednih obrambnih mehanizmov (Wardle et al., 2004; Bezemer \& van Dam, 2005). Dva glavna mehanizma, ki vključujeta spremembe $\mathrm{v}$ rastlinski fiziologiji, sta: spodbujanje rastlinske rasti ter inducirana sistemska obramba (v

\footnotetext{
1 Bušeča vas 1, SI-8263 Cerklje ob Krki, e-mail: anamarija.jagodic@ gmail.com

2 BF, Večna pot 111, SI-1000 Ljubljana, email: matevz.likar@bf.uni-lj.si
} 
nadaljevanju ISO). ISO varuje rastline pred različnimi boleznimi, sprožijo pa jo lahko različne vrste koristnih mikroorganizmov (Sanchez et al., 2005; Van Wees et al., 2008). Prav tako koristni mikroorganizmi vplivajo na nadzemne žuželke (herbivore, naravne sovražnike ter opraševalce) prek rastlinskih posrednikov. Povečana rast rastlin je veljala do nedavnega za enega izmed najpomembnejših mehanizmov interakcij med mikroorganizmi in rastlinami. Zanimanje za ISO je domena novejših raziskav, zato ostaja o tem pojavu še veliko neznanega (Bezemer \& van Dam, 2005; Valenzuela-Soto et al., 2010).

\section{VPLIV MIKROORGANIZMOV NA RAST RASTLIN}

Povečana rast rastlin je eden izmed najpomembnejših pojavov, ki nastane pri simbiozi med rastlinami, mikoriznimi glivami ter dušik fiksirajočimi bakterijami. Tovrsten koristni učinek je še zlasti pomemben $\mathrm{v}$ kmetijstvu, saj $\mathrm{s}$ tem pripomore $\mathrm{k}$ zmanjšani uporabi mineralnih gnojil, kar pa posledično privede do zmanjšanja onesnaženosti kmetijskih zemljǐš in voda (Yang et al., 2009; Weyens et al., 2009). Na primer glive iz rodu Trichoderma spp., spadajo med rast spodbujajoče glive ( $\mathrm{v}$ nadaljevanju RSG), ki so komercialno dostopne in zelo pogosto uporabljene $\mathrm{v}$ kmetijstvu. Trichoderma spp. na rastlino delujejo tako, da spodbudijo sistemsko odpornost (Harman et al., 2004; Trillas et al., 2009; Segarra et al., 2009). Izboljšana rast rastlin pri koristnih simbiozah nastopi zaradi izboljšane prehrane rastlin in zaradi povečane tolerance rastlin na abiotični in biotični stres. Do izboljšane prehrane rastlin pride predvsem zaradi povečanega privzema hranil (npr. fosforja), povečevanja dostopnosti hranil, ki so rastlinam sicer nedostopna in vezave zračnega dušika (Singh et al., 2011; Meena et al., 2017; Felestrino et al., 2017). V zadnjem času se je povečalo zanimanje za tako imenovana mikrobna biognojila, ki poskrbijo za rodovitnost tal, povečajo pridelek in izboljšajo toleranco rastlin na stresne dejavnike (Bhardwaj et al., 2014). Tako so z uporabo tovrstnih biognojil pri pridelavi riža $\mathrm{v}$ delti reke Mekong zmanjšali uporabo kemičnih gnojil za kar $52 \%$ (Nguyen et al., 2017). Učinkovitost rast spodbujajočih bakterij (RSRB) so testirali tudi slovenski raziskovalci. Pri svojem poskusu so uporabili mešanico RSRB (Pseudomonas fluorescens (Flügge 1886) Migula, 1895 in Azospirillum brasilense Tarrand, Krieg \& Döbereiner, 1978) in opazovali učinek le-te na pridelek treh različnih sort krompirja. Poskus je bil izveden tekom vročega in zelo sušnega poletja, kljub temu je bil vpliv mešanice na pridelek vseh treh sort krompirja pozitiven (17\%-31\%). Rezultati njihove raziskave dokazujejo, da ima tovrstna bakterijska mešanica pozitiven vpliv na pridelek krompirja $\mathrm{v}$ sušnih razmerah in pri majhni okužbi s foliarnimi glivičnimi boleznimi ter napadi listnih žuželk (Trdan et al., 2019).
Nekateri mikroorganizmi lahko sintetizirajo rastlinske rastne regulatorje (citokinine, avksine in giberiline) ter $\mathrm{s}$ tem izboljšajo rast rastlin (Baca in Elmerich, 2007; van Loon, 2007; Contreras-Cornejo et al., 2009; Spaepen in Vanderleyden, 2011) in povečajo fotosintezno aktivnost. Znanstveniki so ugotovili, da giberilini, ki jih izločata Azospirillum brasilense in A. lipoferum (Beijerinck 1925) Tarrand et al. 1979 , spodbujata rast poganjkov in povečujeta gostoto korenin pri rižu in koruzi (Baca in Elmerich, 2007). Ugotovljeno je tudi bilo, da mikroorganizmi proizvajajo ACC (1aminociklopropan-1-karboksilat) deaminazo, ki zmanjšuje raven etilena $\mathrm{V}$ rastlinah $\mathrm{z}$ namenom ublažitve sekundarnih učinkov stresa (Glick, 2014; Gamalero in Glick, 2015).

Talni mikroorganizmi lahko prispevajo $\mathrm{k}$ povečani toleranci rastlin na abiotični stres, kot je suša, zasoljenost tal in prisotnost težkih kovin v tleh (Yang et al., 2009; Weyens et al., 2009; Evelin et al., 2009; Bae et al., 2009). Učinek povečane rasti rastlin zaradi delovanja talnih koristnih mikroorganizmov vpliva tudi na interakcije med rastlinami in žuželkami, zaradi česar imajo slednje tudi več hrane (herbivorija: hranjenje $\mathrm{z}$ rastlinskim materialom). Izboljšana sestava hranil $\mathrm{v}$ rastlinah tako vpliva na žuželke na različnih trofičnih nivojih (Schoonhoven et al., 2005; Bukovinszky et al., 2008). Večje vsebnosti dušika pozitivno vplivajo na žuželke, ki se hranijo $\mathrm{z}$ rastlinskimi tkivi in sesanjem rastlinskih sokov iz floema (Schoonhoven et al., 2005). Nenazadnje so tudi zgledi, ki kažejo, da lahko interakcije med rastlinami in koristnimi talnimi mikroorganizmi privedejo do povečane tolerance rastlin na herbivorijo (Bennett et al., 2006; Vannette \& Hunter, 2009). Tako se zaradi izboljšanega prevzema vode in hranil poškodovana tkiva hitreje obnavljajo in nadomestijo manko rastlinske biomase (Herman et al., 2008; Kempel et al., 2009). Kljub temu, da so tovrstni vidiki koristne simbioze med rastlinami in talnimi mikroorganizmi izrednega pomena, še vedno ostajajo slabo preučeni. 


\section{INDUCIRANA SISTEMSKA ODPORNOST PRI RASTLINAH}

Številni talni mikroorganizmi lahko pri rastlinah povzročijo nastanek inducirane obrambe $\mathrm{v}$ sistemskih tkivih (ISO). Načeloma ISO sprožijo rast spodbujajoče bakterije (RSRB), kot so Pseudomonas in Bacillus spp. (Kloepper et al., 2004; Van Wees et al., 2008; Van der Ent et al., 2009), vendar zadnje raziskave kažejo, da lahko ISO spodbudijo tudi mikorizne glive (Pozo \& Azcon Aguilar, 2007; Trillas et al., 2009;), endofitske glive (Stein et al., 2008) ter rast spodbujajoče glive (v nadaljevanju RSG) (Harman et al., 2004; Segarra et al., 2009). ISO ima določene lastnosti, po katerih se razlikuje od ostalih sistemskih toleranc. Tako jo spodbudijo nepatogeni organizmi, pri čemer se sproži delovanje obrambnih genov, kar privede do povečane odpornosti na škodljive organizme ter vključuje odzivnost rastline na rastlinske rastne regulatorje, kot sta jasmonska kislina (JA) in etilen (Van Wees et al., 2008; Van der Ent et al., 2009). Pri tem je potrebno poudariti, da je ISO pogojena predvsem s povečano dovzetnostjo rastline za rastlinske rastne regulatorje in ne $\mathrm{s}$ povečano produkcijo rastlinskih rastnih regulatorjev (Van der Ent et al., 2009). Mehanizmi, ki uravnavajo ISO ter obrambne strategije pri herbivoriji, se deloma prekrivajo (Pieterse \& Dick, 2007; Pieterse et al., 2009,). Odziv rastlin na žuželke, ki povzročajo poškodbe $\mathrm{z}$ grizenjem rastlin, je največkrat pogojen $\mathrm{s}$ sproščanjem JA (Zheng et al., 2007; Van Oosten et al., 2008;). Enako velja tudi za odziv rastlin na žuželke, ki so škodljive zaradi sesanja (npr. listne uši) (ZhuSalzman et al., 2005; Zarate et al., 2007), JA je rastlinski rastni regulator, ki ima pomembno vlogo pri ISO in je tudi zelo pomembna pri obrambi rastlin pred napadom škodljivih žuželčjih vrst. Zato lahko rečemo, da koristni talni mikroorganizmi vplivajo na interakcije med rastlinami in žuželkami.

Učinkovitost ISO na različne patogene organizme je bila dokazana na številnih rastlinskih primerih (Van Oosten et al., 2008), pri čemer lahko vzpostavitev obrambnih reakcij poteče po nekoliko različnih poteh. Prvi korak pri aktiviranju ISO, je prepoznavanje molekularnih vzorcev (elicitorjev), ki jih izločajo mikroorganizmi $\left(\mathrm{Fe}^{3+}\right.$, siderofori, antibiotiki, hlapljive organske snovi) (Bakker et al., 2007; Van Wees et al., 2008; Van der Ent et al., 2009). Ko rastlina prepozna prej navedene spojine, se aktvira gen za transkripcijo MYB72 v koreninah. Mutirane rastline myb72 se na napad žuželk in patogenih organizmov ne odzovejo $\mathrm{z}$ ISO tudi, če so kolonizirane s RSRB ali RSG (Van der Ent et al., 2008; Segarra et al., 2009), kar kaže na to, da ima transkripcijski faktor MYB72 ključno vlogo pri nastanku ISO. Tudi transkripcijski faktor MYC2, ki uravnava izločanje JA, je bil $\mathrm{V}$ preteklih raziskavah ugotovljen kot pomemben regulator ISO pri navadnem repnjakovcu (Arabidopsis thaliana L.) (Pozo et al., 2008; Van der Ent et al., 2009). RSBR bakterija Bacillus subtilis (Ehrenberg 1835) Cohn 1872 pa je pri paradižniku vplivala na dvig obrambne sposobnosti proti rastlinjakovemu ščitkarju (Trialeurodes vaporariorum Westwood,1856) po tako od JA-odvisni poti kot tudi po JA-neodvisni poti (Valenzuela-Soto et al., 2010). V primeru mikoriznih gliv, ko so le-te $\mathrm{v}$ začetnih stopnjah kolonizacije prepoznane kot biotrof, kar inducira začetek obrambnih reakcij $\mathrm{s}$ spremembami $\mathrm{v}$ transkripciji in ravni rastnih regulatorjev. Fiorilli et al. (2011) so opazili znatne spremembe $\mathrm{V}$ transkriptomu paradižnika med kolonizacijo z arbuskularno mikorizno glivo Glomus mosseae (T.H. Nicolson \& Gerd.) Gerd. \& Trappe (1974). Pri tem je prišlo do sprememb izražanja genov primarnega in sekundarnega metabolizma $\mathrm{v}$ koreninah in poganjkih, vključno $\mathrm{z}$ indukcijo obrambnih reakcij poveznih z biotskim stresom. Rizosferni mikroorganizmi in endofiti lahko tako sprožijo različne mehanizme, ki vzpodbudijo obrambo rastline pred herbovornimi žuželkami.

Kljub temu, da je poznavanje molekularnega mehanizma pri ISO izrednega pomena, za samo poznavanje le-te, na to temo še ni bilo izvedenih veliko raziskav. Bodoče raziskave mehanizmov delovanja ISO bi nam vsekakor omogočile globlji vpogled in boljše razumevanje tovrstnih interakcij (Van Oosten et al., 2008; Valenzuela-Soto et al., 2010)

\section{VPLIV NA NADZEMSKE ŠKODLJIVE ORGANIZME}

Koristni talni mikroorganizmi lahko spodbudijo tudi rastlinsko obrambo pred nadzemskimi herbivori. Tako so v primeru topola Populus x canescens (Aiton) Sm. ugotovili, da je kolonizacija $\mathrm{z}$ ektomikorizno glivo Laccaria laccata (Scop.) Cooke zaradi sprememb v transkriptomu rastlinskemu gostitelju omogočila uporabo snovi, ki so bile učinkovitejše pri obrambi pred hroščem Chrysomela populi, (L., 1758), kot pa snovi, ki so jih uporabili nekolonizirani topoli (Kaling et al., 2018).

Pri tem pa ne smemo tudi zanemariti učinka številnih abiotskih in biotiskih dejavnikov na interakcije na relaciji mikroorganizem-rastlina-herbivor. Tako lahko na obrambo rastlin pred herbivori vpliva tudi razvojni stadij rastline (Barton \& Koricheva, 2010). Upoštevati moramo tudi dejstvo, da so interakcije na relaciji 
mikroorganizmi-rastline-herbivori, vrstno specifične, tako pri interakcijah z eno vrsto mikroorganizma kot pri mikrobnih združbah (Goverde et al., 2000; Gange et al., 2005;). Znanstveniki so na zgledu riža (Oryza sativa L.) uporabili kombinacijo različnih RSRB sevov, pri čemer so opazili, da je imela kombinacija močnejši negativen učinek na delovanje ličinke Cnaphalocrocis medinalis (Guenée, 1854) ter na aktivnost encimov, ki delujejo pri obrambi rastlin (tripsin inhibitorji, polifenol oksidaze), kot pa če bi v poskus bili vključeni samo posamezni sevi (Saravanakumar et al., 2007; Saravanakumar et al., 2008).

Prav tako so bili zabeleženi učinki abiotskega stresa na delovanje koristnih mikroorganizmov (Vidal, 1996; Borowiez, 1997). To so ugotovili na zgledu endofitske glive Acremonium strictum, ki je povečala smrtnost rastlinjakovega ščitkarja (Trialeurodes vaporarium Westwood, 1856) pri paradižniku, ki je bil izpostavljen suši. Pri optimalni vlagi in preskrbljenosti z vodo gliva ni imela učinka na smrtnost rastlinjakovega ščitkarja (Vidal, 1996).

Izid interakcij med rastlinami, mikrobi in herbivori je pogojen $\mathrm{z}$ načinom prehranjevanja škodljivca (Van Oosten et al., 2008; Gehring \& Bennett; 2009; Hartley \& Gange, 2009; Koricheva et al., 2009). Herbivori, ki spadajo med generaliste, so tako bolj dovzetni na toksične sekundarne metabolite, ki jih izločajo rastline, kot pa specialisti. Slednji tovrstne komponente celo uporabljajo za lociranje svojega gostitelja (Schoonhoven et al., 2005). Pogojenost interakcij $\mathrm{z}$ načinom prehranjevanja so dokazali $\mathrm{z}$ raziskavo na navadnem repnjakovcu, kjer obramba rastline z ISO, ki jo je vzpodbudila bakterija Pseudomonas fluorescens, ni imela učinka pri napadu gosenice repnega belina (Pieris rapae L., 1758) (specialist) (Van Oosten et al., 2008).

Ugotovljeno je bilo, da na ISO vpliva tudi oblika ustnega aparata (Gehring \& Bennett; 2009, Kempel \& al. 2009, Hartley \& Gange, 2009, Koricheva \& al. 2009). Številni rastlinski sekundarni metaboliti, kot so glukozinolati in cianogeni glikozidi, po hidrolizi z encimi tvorijo toksične produkte (Schoonhoven et al., 2005). Tovrstni encimi so prostorsko ločeni od substratov in pridejo $\mathrm{v}$ stik $\mathrm{z}$ njimi šele pri poškodbi celic zaradi napada herbivorov. Škodljivi organizmi, ki se prehranjujejo s sesanjem rastlinskih sokov, vstavijo svoje bodalo intercelularno in pri tem ne poškodujejo celičnega tkiva, zato hidrolitski encimi ne pridejo v stik s sekundarnimi metaboliti. Zaradi tega takšen način obrambe na slednje nima učinka (Gehring \& Bennett, 2009; Kempel et al., 2009; Hartley \& Gange, 2009; Koricheva et al., 2009).

\section{VPLIV NA NARAVNE SOVRAŽNIKE HERBIVOROV IN OPRAŠEVALCE}

Rastline pri napadu herbivorov izločajo kompleksne mešanice hlapnih organskih snovi, ki privabljajo v svojo bližino naravne sovražnike herbivorov (Vet \& Dicke, 1992; Dicke et al., 2009; Zhang et al., 2009; Snoeren et al., 2009). Takšen način obrambe pred herbivori imenujemo posredna obramba. Izločanje JA uvrščamo med posredne načine obrambe in je ena izmed najpomembnejših signalizacijskih poti, ki vplivajo na sproščanje hlapnih organskih snovi. Zato multitrofične interakcije, ki vplivajo na signalizacijske poti JA, posledično vplivajo tudi na sestavo hlapnih snovi (Dicke et al., 2009; Snoeren et al., 2009). Tako lahko pričakujemo, da bodo koristni mikroorganizmi, ki vzpodbudijo JA signalizacijske poti, imeli učinek tudi na izločanje in sestavo hlapnih organskih komponent. Eden izmed zgledov, ki kaže na spremembe v sestavi hlapnih organski snovi pri ISO zaradi koristnih mikroorganizmov, je ta, da so mikorizne rastline izločale manj seskviterpenov, kot nemikorizne rastline. Pri tem je potrebno poudariti, da učinek tovrstnih emisij hlapnih organskih komponent, ki nastanejo pri ISO, zaradi koristnih mikroorganizmov še ni bil natančno preučen (Fontana et al., 2009). Kolonizacija rastlin s koristnimi mikroorganizmi lahko tako vpliva na povečanost napada, zmogljivost in na privabljanje naravnih sovražnikov herbivorov (Guerrieri et al., 2004; Hempel et al., 2009), tudi če je število gostiteljskih herbivorov manjše kot število gostiteljskih herbivorov na nekoloniziranih rastlinah (Saravanakumar et al., 2008). Pri tovrstnih študijah znanstveniki ugotavljajo, da posredna obramba, ki nastopi zaradi koristnih mikroorganizmov, vzpodbudi spremembe pri izločanju hlapnih organskih komponent, ki sprožijo privabljanje naravnih sovražnikov herbivorov.

Zadnje čase znanstveniki vse več pozornosti posvečajo interakcijam med rastlinami, talnimi koristnimi mikroorganizmi ter opraševalci (Gange \& Smith, 2005; Cahill et al., 2008). Ugotovili so povečano številčnost opraševalcev na preučevanih rastlinah in večje število semen kot pri kontrolnih rastlinah, ki niso bile kolonizirane (Gange \& Smith, 2005; Cahill et al., 2008). Učinek hlapnih organskih snovi v tovrstnih interakcijah je še vedno premalo preučen. 


\section{VPLIV NADZEMSKIH HERBIVOROV NA KORISTNE TALNE MIKROORGANIZME}

Vpliv nadzemske herbivorije na talne koristne mikroorganizme je manj preučevan zgled interakcij (Schoonhoven et al., 2005; Shultz et al., 2009; Sinka et al., 2009; Johnson et al., 2009). Znanstveniki so v nekaterih zgledih odkrili, da lahko hebivorija privede do zmanjšane mikorizne kolonizacije (Gehring in Whitham, 1991; Schoonhoven et al., 2005; Gange, 2007), lahko jo poveča ali pa celo nima učinka (Kosola et al., 2004). V nekaterih zgledih pa so opazili, da sta stopnja mikorizne kolonizacije in herbivorija negativno korelirali (Schoonhoven et al., 2005; Gange, 2007).

Ugotovljeno je bilo, da ima pri takšnih interakcijah zelo pomembno vlogo ogljik, ki ga rastline naložijo $\mathrm{v}$ koreninah (Schoonhoven et al., 2005). Nadzemna herbivorija namreč sproži povečano nalaganje ogljika $\mathrm{v}$ koreninah, s čimer si rastline zagotovijo obnovo po napadu (Schwachtje et al., 2006; Schwachtje \& Baldwin, 2008; Erb et al., 2009; Johnson et al., 2009). Nalaganje ogljika pa je seveda pogojeno tudi s starostjo rastline, pri čemer je najmanjše v stadiju reprodukcije (Wamberg et al., 2003). Sistem je še bolj kompleksen, saj se zaradi nadzemne herbivorije začnejo izločati tudi sekundarni metaboliti in hlapne organske snovi (Soler et al., 2007; Erb et al., 2009). Poleg tega lahko talni mikroorganizmi delujejo tudi škodljivo $\mathrm{v}$ določenih razmerah (Jones \& Smith, 2004,; Soto et al., 2009), na katere lahko vplivajo obrambni mehanizmi rastline, ki jih vzpostavi pri napadu nadzemnih herbivorov (Heil et al., 2009).

Prav tako nadzemna herbivorija vpliva na sestavo in izločanje koreninskih izločkov (Bezemer \& van Dam, 2005), ki imajo pomembno vlogo pri interakcijah rastlina-mikroorganizmi v rizosferi (Rudrappa et al., 2008). Koreninski izločki vsebujejo različne metabolite, kot so ogljikovi hidrati in organske kisline, ki stimulirajo bakterijsko mobilnost in privabljajo bakterije h koreninam rastlin (Rudrappa et al., 2008). Iz zgoraj navedenih zgledov nadzemnih in talnih interakcij lahko povzamemo, da so njihovi učinki dvosmerni ter, da predstavljajo področje, na katerem bi bilo potrebno opraviti še kar nekaj raziskav.

\section{ZAKLJUČEK}

Mehanizmi, vključeni $\mathrm{v}$ interakcije med rastlinami, mikroorganizmi in žuželkami, delujejo predvsem $\mathrm{v}$ smeri povečane rasti rastlin in inducirane obrambe pred škodljivimi organizmi. Na končni izid ima vpliv interakcija med samimi obrambnimi mehanizmi, ki jih rastlina uporabi $\mathrm{v}$ primeru napada. $\mathrm{V}$ znanosti je primer ISO zaradi koristnih talnih mikroorganizmov dobro znan, veliko manj pa je znanega o inducirani obrambi pri napadih škodljivih žuželčjih vrst. Spodbujena odpornost pri herbivoriji pa ni edini mehanizem prek katerega talni koristni mikroorganizmi vplivajo na interakcije med rastlinami in žuželkami. Znano je tudi, da lahko koristni talni mikroorganizmi povečajo učinkovitost naravnih sovražnikov škodljivih žuželk ter $\mathrm{s}$ tem zmanjšajo negativni vpliv na rastlino. Tudi $\mathrm{v}$ primeru, ko posredni ali neposredni mehanizmi obrambe niso uspešni, lahko talni mikroorganizmi pripomorejo $\mathrm{k}$ povečanju rastlinske biomase in pridelka ter na tak način okrepijo toleranco rastline proti škodljivim organizmom. V nadaljnjih raziskavah bi se zagotovo morali osredotočiti na interakcije koloniziranih rastlin $\mathrm{s}$ koristnimi mikroorganizmi, opraševalci ter naravnimi sovražniki škodljivih žuželk, saj lahko rezultati tovrstnih raziskav znatno pripomorejo pri optimizaciji uporabe fitofarmacevtskih in biotičnih sredstev za zatiranje škodljivcev v kmetijstvu. Prav tako bi se morali žlahtnitelji gojenih rastlin osredotočati na lastnosti rastlin, ki spodbujajo koristne interakcije med rastlinami in mikroorganizmi.

\section{ZAHVALA}

Prispevek je nastal v okviru predmeta Ekologija na Oddelku za biologijo Biotehniške fakultete.

\section{LITERATURA}

Baca B.E., Elmerich C. (2007). Microbial production of plant hormones. Associative and Endophytic Nitrogen-Fixing Bacteria and Cyanobacterial
Associations, Springer, Netherlands, 113-143. https://doi.org/10.1007/1-4020-3546-2_6 
Bae H. et al. (2009). The beneficial endophyte Trichoderma hamatum isolate DIS $219 \mathrm{~b}$ promotes growth and delays the onset of the drought response in Theobroma cacao. Journal of Experimental Botany, 60, 3279-3295. https://doi.org/10.1007/14020-3546-2_6

Bakker P. et al. (2007). Induced systemic resistance by fluorescent Pseudomonas spp.. Phytopathology, 97, 239-243. https://doi.org/10.1094/PHYTO-97-20239

Barton K. E., Koricheva J. (2010). The ontogeny of plant defense and herbivory: characterizing general patterns using meta-analysis. American Naturalist, 175, 481-493. https://doi.org/10.1086/650722

Bennett A. E. et al. (2010). Three-way interactions among mutualistic mycorrhizal fungi, plants, and plant enemies: hypotheses and synthesis. American Naturalist, 167, 141-152.

Bezemer T. M., van Dam N. M. (2005). Linking aboveground and belowground interactions via induced plant defenses. Trends in Ecology \& Evolution, 20, 617-624. https://doi.org/10.1016/j.tree.2005.08.006

Bhardwaj D. et al. (2014). Biofertilizers function as key player in sustainable agriculture by improving soil fertility, plant tolerance and crop productivity. Microbial Cell Factories, 13, 66. https://doi.org/10.1186/1475-2859-13-66

Borowicz V.A. (1997). A fungal root symbiont modifies plant resistance to an insect herbivore. Oecologia, 112 , 534-542. https://doi.org/10.1007/s004420050342

Bukovinszky T. et al. (2008). Direct and indirect effect of resource quality on food web structure. Science, 319 , https://doi.org/10.1126/science.1148310 804-807.

Cahill J.F. et al. (2008). Disruption of a belowground mutualism alters interactions between plants and their floral visitors. Ecology, 89, 1791-1801. https://doi.org/10.1890/07-0719.1

Contreras-Cornejo H.A. et al. (2009). Trichoderma virens, a plant beneficial fungus, enhances biomass production and promotes leteral root growth through an auxin-dependent mechanism in Arabidopsis. Plant Physiology, 149, 1579-1592. https://doi.org/10.1104/pp.108.130369

Dicke M. et al. (2009). Chemical complexity of volatiles from plants induced by multiple attack. Nature Chemical Biology, 5, 317-324. https://doi.org/10.1038/nchembio.169
Erb M. et al. (2009). The underestimated role of roots in defense against leaf attackers. Trends in Plant Science, 14, 653-659. https://doi.org/10.1016/j.tplants.2009.08.006

Evelin H. et al. (2009). Arbuscular mycorrhizal fungi in alleviation of salt stress: a review. Annals Botany, 104, 1263-1280 https://doi.org/10.1093/aob/mcp251

Felestrino E.B. et al. (2017). Plant growth peooting bacteria associated with Langsdorffia hypogaearhizosphere-host biological interface: a neglected model of bacterial prospection. Frontiers in Microbiology. https://doi.org/10.3389/fmicb.2017.00172

Fiorilli, V. et al. (2011). The arbuscular mycorrhizal symbiosis reduces disease severity in tomato plants infected by Botrytis cinerea. Journal of Plant Pathology, 93, 237-242.

Fontana A. et al. (2009). The effects of arbuscular mycorrhizal fungi on direct and indirect defense metabolites of Plantago lanceolata L. Journal of Chemical Ecology, 35, 833-843. https://doi.org/10.1007/s10886-009-9654-0

Gamalero E., Glick B.R. (2015). Bacterial modulation of plant ethylene levels. Plant Physiology, 169, 1322. https://doi.org/10.1104/pp.15.00284

Gange A.C. et. al. (2005). Ecological specificity of arbuscular mycorrhizal: evidence from foliar and seed-feeding insects. Ecology, 86, 603-611. https://doi.org/10.1890/04-0967

Gange A.C., Smith A.K. (2005). Arbuscular mycorrhizal fungi influence visitation rates of pollinating insects. Ecological Entomology, 30, 600-606. https://doi.org/10.1111/j.03076946.2005.00732.x

Gange A.C. (2007). Insect-mycorrhizal interactions: patterns, processes and consequences. In: Ecological Communities: Plant Mediation in Indirect Interaction Webs (Ohgushi T. et. al., eds), pp. 124-143. Cambridge University Press. https://doi.org/10.1017/CBO9780511542701.007

Gehring C.A., Whitham T.G. (1991). Herbivore-driven mycorrhizal mutualism in insect-susceptible pinyon pine. Nature, 353, 556-557. https://doi.org/10.1038/353556a0

Gehring C., Bennett A. (2009). Mycorrhizal fungalplant-insect interactions: the importance of a community approach. Environmental Entomology, 38, 93-102. https://doi.org/10.1603/022.038.0111

Glick B. R. (2014). Bacteria with ACC deaminase can promote plant growth and help to feed the world. 
Microbiological Research, 169, 30-39. https://doi.org/10.1016/j.micres.2013.09.009

Goverde M. et. al. (2000). Arbuscular mycorrhizal fungi influence life history traits of a lepidopteran herbivore. Oecologia, 125, 362-369. https://doi.org/10.1007/s004420000465

Guerrieri E. et. al. (2004). Do interactions between plant roots and the rhizosphere affect parasitoid behaviour? Ecological Entomology, 29, 753-756. https://doi.org/10.1111/j.0307-6946.2004.00644.x

Harman G. E. et. al. (2004). Trichoderma speciesopportunistic, avirulent plant symbionts. Nature Reviews Microbiology, 2, 43-56. https://doi.org/10.1038/nrmicro797

Hartley S. E., Gange A. C. (2009). Impacts of plant symbiotic fungi on insect herbivores: mutualism in a multitrophic context. Annual Review of Entomology, 54, 323-342. https://doi.org/10.1146/annurev.ento.54.110807.09 0614

Heil M. et. al. (2009). Ecological consequences of plant defence signalling. Advances in Botanical Research, 51, 667-716. https://doi.org/10.1016/S0065-2296(09)51015-4

Hempel S. et. al. (2009). Specific bottom-up effects of arbuscular mycorrhizal fungi across a plantherbivore-parasitoid system. Oecologia, 160, 267277. https://doi.org/10.1007/s00442-009-1294-0

Herman M. A. B. et. al. (2008). Effects of plant growthpromoting rhizobacteria on bell pepper production and green peach aphid infestations in New York. Crop Protection, 27, 996-1002. https://doi.org/10.1016/j.cropro.2007.12.004

Johnson S. N. et. al. (2009). Reappraising the role of plant nutrients as mediators of interactions between root- and foiliar-feeding insects. Functional Ecology, 23, 699-706. https://doi.org/10.1111/j.1365-2435.2009.01550.x

Jones M. D., Smith S. E. (2004). Exploring functional definitions of mycorrhizas: Are mycorrhizas always mutualisms? Canadian Journal of Botany, 82, 1089-1109. https://doi.org/10.1139/b04-110

Kaling M. et al. (2018). Mycorrhiza-Triggered Transcriptomic and Metabolomic Networks Impinge on Herbivore Fitness. Plant Physiology. https://doi.org/10.1104/pp.17.01810

Kempel A. et. al. (2009). Symbiotic soil microorganisms as players in aboveground plantherbivore interactions - the role of rhizobia. Oikos, $118, \quad 634-640 . \quad$ https://doi.org/10.1111/j.16000706.2009.17418.x
Kloepper J. W. et. al. (2004). Induced systemic resistance and promotion of plant growth by Bacillus spp. Phytopathology, 94, 1259-1266. https://doi.org/10.1094/PHYTO.2004.94.11.1259

Koricheva J. et. al. (2009). Effects of mycorrhizal fungi on insect herbivores: a meta-analysis. Ecology, 90, 2088-2097. https://doi.org/10.1890/08-1555.1

Kosola K.R. et. al. (2004). Resilience of mycorrhizal fungi on defoliated and fertilized hybrid poplars. Canadian Journal of Botany, 82, 671-680. https://doi.org/10.1139/b04-038

Meena K.K. et al. (2017). Abiotic stress responses and microbe-mediated mitigation in plants: the omics strategies. Frontiers in Plant Science, 8, 172. https://doi.org/10.3389/fpls.2017.00172

Nguyen T.H. et al. (2017). BioGro: A plant growthpromoting biofertilizer validated by 15 years research from laboartory selection to rice farmer's fields od the Mekong Delta. Agro-Enviromental Sustainability, Springer International Publishing (2017) pp. 237-254. https://doi.org/10.1007/978-3319-49724-2_11

Pieterse C. M. J., Dicke M. (2007). Plant interactions with microbes and insects: from molecular mechanisms to ecology. Trends in Plant Science, 12 , 564-569. https://doi.org/10.1016/j.tplants.2007.09.004

Pieterse C. M. J. et. al. (2009). Networking by smallmolecule hormones in plant immunity. Nature Chemical Biology, 5, 308-316. https://doi.org/10.1038/nchembio.164

Pieterse C.M. et. al. (2012). Hormonal modulation of plant immunity. Annual review of cell and developmental biology, 28, 489-521. https://doi.org/10.1146/annurev-cellbio-092910154055

Pozo M. J., Azcon-Aguilar C. (2007). Unraveling mycorrhiza-induced resistance. Current Opinion of Plant Biology, 10, 393-398. https://doi.org/10.1016/j.pbi.2007.05.004

Pozo M.J. et al. (2008). Transcription factor MYC2 is involved in priming for enhanced defense during rhizobacteria-induced systemic resistance in Arabidopsis thaliana. New Phytologist, 180, 511523. $\quad$ https://doi.org/10.1111/j.14698137.2008.02578.x

Rudrappa T. et. al. (2008). Root-secreted malic acid recruits beneficial soil bacteria. Plant Physiology, 148 , 1547-1556. https://doi.org/10.1104/pp.108.127613

Sanchez L. et. al. (2005). Pseudomonas fluorescens and Glomus mosseae trigger DMI3-dependent

Acta agriculturae Slovenica, 113 - 1, marec 2019 
activation of genes related to a signal transduction pathway in roots of Medicago truncatula. Plant Physiology, 139, 1065-1077. https://doi.org/10.1104/pp.105.067603

Saravanakumar D. et. al. (2007). Pseudomonas-induced defence molecules in rice plants against leaffolder (Cnaphalocrocis medinalis) pest. Pest Management Science, 63, 714-721. https://doi.org/10.1002/ps.1381

Saravanakumar D. et. al. (2008). Pseudomonas fluorescens enhances resistance and natural enemy population in rice plants against leaffolder pest. Journal of Applied Entomology, 132, 469-479. https://doi.org/10.1111/j.1439-0418.2008.01278.x

Schoonhoven L. M. et. al., eds (2005). Insect-Plant Biology. Oxford University Press.

Schwachtje J. et. al. (2006). SNF1-related kinases allow plants to tolerate herbivory by allocating carbon to roots. Proceedings of the National Academy of Sciences of the United States of America National Academy of Sciences, 103, 12935-12940. https://doi.org/10.1073/pnas.0602316103

Schwachtje J., Baldwin I. T. (2008). Why does herbivore attack reconfigure primary metabolism? Plant Physiology, 146, 845-851. https://doi.org/10.1104/pp.107.112490

Segarra G. et. al. (2009). MYB72, a node of convergence in induced systemic resistance triggered by a fungal and a bacterial beneficial microbe. Plant Biology, 11, 90-96. https://doi.org/10.1111/j.1438-8677.2008.00162.x

Singh D.P. et al. (2011). Cyanobacteria-mediated phenylpropanoides and phytohormones in rice (Oryza sativa) enhance plant growth and stress tolerance. Antonie van Leeuwenhoek, 100, 557568. https://doi.org/10.1007/s10482-011-9611-0

Sinka M. et. al. (2009). Collembola respond to aphid herbivory but not to honeydew addition. Ecological Entomology, 34, 588-594. https://doi.org/10.1111/j.1365-2311.2009.01106.x

Snoeren T.A. L. et. al. (2009). Multidisciplinary approach to unravelling the relative contribution of different oxylipins in indirect defense of Arabidopsis thaliana. Journal of Chemical Ecology, 35, 1021-1031. https://doi.org/10.1007/s10886-009-9696-3

Soler R. et. al. (2007). Impact of foliar herbivory on the development of a root-feeding insects and its parasitoid. Oecologia, 152, 257-264. https://doi.org/10.1007/s00442-006-0649-z
Soto M. et. al. (2009). Mutualism versus pathogenesis: The give-and-take in plant-bacteria interactions. Cell Microbiology, 11, 381-388. https://doi.org/10.1111/j.1462-5822.2009.01282.x

Spaepen S., Vanderleyden J. (2011). Auxiin and plant microbe interactions. Cold Spring Harbor perspectives in biology, 3, 1438. https://doi.org/10.1101/cshperspect.a001438

Stein E. et. al.( 2008). Systemic resistance in Arabidopsis conferred by the mycorrhizal fungus Piriformospora indica requires jasmonic acid signaling and the cytoplasmic function of NPR1. Plant Cell Physiology, 49, 1747-1751. https://doi.org/10.1093/pcp/pcn147

Sthultz C.M. et. al. (2009). Genetically based susceptibility to herbivory influences the ectomycorrhizal fungal communities of a foundation tree species. New Phytologist, 184, 657667. https://doi.org/10.1111/j.14698137.2009.03016.x

Trillas M. I. et. al. (2009). Interactions between nonpathogenic fungi and plants. Advances in Botanical Research, 51, 321-359. https://doi.org/10.1016/S0065-2296(09)51008-7

Trdan S. et. al. (2019). The effect of a mixture of two plant growth-promoting bacteria from Argentina on the yield of potato, and occurrence of primary potato diseases and pest-short communication. Acta Agriculturae Scandinavica, 69, 89-94.

Valenzuela-Soto J. H. et. al. (2010). Inoculation of tomato plants Solanum lycopersicum with growthpromoting Bacillus subtilis retards whitefly Bemisia tabaci development. Planta, 231, 397-410. https://doi.org/10.1007/s00425-009-1061-9

Vannette R.L. and Hunter M.D. (2009). Mycorrhizal fungi as mediators of defence against insect pests in agricultural systems. Agricultural and Forest Entomology, 11, 351-358. https://doi.org/10.1111/j.1461-9563.2009.00445.x

Van der Ent S. et al. (2008). MYB72 is reqired in early signaling steps of rhizobacteria-induced systemic resistance in Arabidopsis. Plant Physiology, 146, 1293-1304. https://doi.org/10.1104/pp.107.113829

Van der Ent S. et al. (2009). Priming of plant innate immunity by rhizobacteria and beta-aminobutyric acid: differences and similarities in regulation. New Phytologist, 183, 419-431. https://doi.org/10.1111/j.1469-8137.2009.02851.x

Van der Ent S. et. al. (2009). Jasmonate signaling in plant interactions with resistance-inducing beneficial microbes. Phytochemistry, 70, 15811588. Van Loon L. C. (2007). Plant responses to 
plant growth-promoting rhizobacteria. European Journal of Plant Pathology, 119, 234-254. https://doi.org/10.1016/j.phytochem.2009.06.009

Van Loon L. C. (2007). Plant responses to plant growthpromoting rhizobacteria. European Journal of Plant Pathology, 119, 234-254. https://doi.org/10.1007/s10658-007-9165-1

Van Oosten V. R. et. al. (2008). Differential effectiveness of microbially induced resistance against herbivorous insects in Arabidopsis. Molecular Plant-Microbe Interactions, 21, 919930. https://doi.org/10.1094/MPMI-21-7-0919

Van Wees S. C. M. et. al. (2008). Plant immune responses triggered by beneficial microbes. Current Opinion of Plant Biology, 11, 443-448. https://doi.org/10.1016/j.pbi.2008.05.005

Vet L. E .M., Dicke M. (1992). Ecology of infochemical use by natural enemies in a tritrophic context. Annual Review of Entomology, 37, 141-172. https://doi.org/10.1146/annurev.en.37.010192.0010 41

Vidal S. (1996). Changes in suitability of tomato for whiteflies mediated by a non-pathogenic endophytic fungus. Entomologia experimentalis et applicata, $80, \quad 272-274$. https://doi.org/10.1111/j.1570-7458.1996.tb00933.x

Wamberg C. et. al. (2003). Interactions between foliarfeeding insects, mycorrhizal fungi and rhizosphere protozoa on pea plants. Pedobiologia, 47, 281-287. https://doi.org/10.1078/0031-4056-00191

Wardle D. A. et. al. (2004). Ecological linkages between aboveground and belowground biota. Science, 304, 1629-1633. https://doi.org/10.1126/science.1094875

Weyens N. et. al. (2009). Exploiting plant-microbe partnerships to improve biomass productions and remediation. Trends in Biotechnology, 27, 591-598. https://doi.org/10.1016/j.tibtech.2009.07.006

Yang J. et. al. (2009). Rhizosphere bacteria help plants tolerate abiotic stress. Trends in Plant Science, 14, 1-4. https://doi.org/10.1016/j.tplants.2008.10.004

Zarate S. I. et. al. (2007). Silverleaf whitefly induces salicylic acid defenses and suppresses effectual jasmonic acid defenses. Plant Physiology, 143, 866-875. https://doi.org/10.1104/pp.106.090035

Zhang P. J. et. al. (2009). Whiteflies interfere with indirect plant defense against spider mites in Lima bean. Proceedings of the National Academy of Sciences of the United States of America National Academy of Sciences, 106, 21202-21207. https://doi.org/10.1073/pnas.0907890106

Zhu-Salzman K. et. al. (2005). Molecular strategies of plant defense and insect counter-defense. Insect Science, 12, 3-15. https://doi.org/10.1111/j.16729609.2005.00002.x 